\title{
THE ROLE OF THE MULTIDISCIPLINARY TEAM MEETING IN AN ANTIRETROVIRAL TREATMENT PROGRAMME
}

\author{
C van Deventer, MD ChB, FCFP (SA), MFamMed (Med) \\ Witwatersrand \\ M Radebe, $M B$ \\ Potchefstroom Hospital, North West
}

Principal Family Physician, Southern District, North West Province, and Senior Lecturer, Rural Health and Family Medicine, University of the

The importance of adherence in the management of patients on combination antiretroviral therapy has been well documented. ${ }^{1-6}$ However, for sustainability of the overall programme adequate patient 'tracking' is required in order to understand where the programme may be failing.

Fogarty et al..$^{6}$ reviewed 18 descriptive studies in published articles and 57 conference proceedings and found over 200 variables regarding patient adherence to antiretroviral therapy (ART), falling into four broad areas:

factors related to treatment regimen

- social and psychological factors

- institutional resources

- personal attributes.

They found that more complex regimens were associated with decreased adherence. Social and psychological factors reflecting emotional adjustment to HIV/AIDS and provider support were associated with improved adherence, as was access to institutional resources. Personal attributes showed a mixed relationship; gender was not consistently related to adherence, but younger age, minority status, and a history of substance abuse were often associated with non-adherence. An intervention search yielded 16 interventions employing a wide range of behavioural, cognitive and affective strategies. However, evidence of effectiveness of the interventions appeared to be poor.

According to Nischal et al., ${ }^{7}$ studies have indicated that at least 95\% adherence to ART regimens is optimal. It has been demonstrated that a 10\% higher level of adherence results in a $21 \%$ reduction in disease progression. The various factors affecting success of ART are social aspects such as motivation to begin therapy, ability to adhere to therapy, lifestyle pattern, financial support, family support, pros and cons of starting therapy, and pharmacological aspects such as tolerability of the regimen and availability of the drugs. Furthermore, the regimen's pill burden, dosing frequency, food requirements, convenience, toxicity and drug interaction profile compared with other regimens need to be considered before starting ART. Lack of trust between clinician and patient, active drug and alcohol use, active mental illness (e.g. depression), lack of patient education, inability of patients to identify their medications, and lack of reliable access to primary medical care or medication may all contribute to inadequate adherence.

Mehta et al. ${ }^{4}$ found the following factors in an extensive study on adherence: Adherence increases with age, except in the most elderly (those aged over 75 years). ${ }^{8}$ It is known that the very elderly often have comorbidities such as vision, hearing or memory impairment as well as multiple chronic illnesses. In several studies of patients with HIV infection, chronic illness, mental illness, older age and male gender were associated with decreased adherence. Lower socio-economic status (SES) has been shown to be another contributor to decreased adherence. ${ }^{9}$ Socio-economic factors specifically related to decreased adherence are unstable or poor housing, low income and low level of education. The presence of psychiatric illness is commonly associated with decreased adherence. ${ }^{10}$ Other psychological factors affecting adherence among the mentally ill are hostility, guilt, anxiety, paranoia and grandiosity. ${ }^{11}$ In contrast, in a prospective study of HIV-infected individuals, adherent patients (defined as $\geq 80 \%$ adherence) had significantly less depression than non-compliant patients. ${ }^{12}$ Negative attitudes about medications or illness may also interfere with patient adherence. Among the mentally ill, reasons cited for not taking medications were fear of addiction and the belief that medication use was a sign of weakness. ${ }^{13}$ Among HIVinfected patients, attitudes and beliefs related to decreased adherence included the patient's acceptance/ perception of disease, and perceived lack of benefit. ${ }^{13}$ 


\section{THE POTCHEFSTROOM WELLNESS CLINIC}

The ART clinic at Potchefstroom Hospital, known as the Wellness Clinic, was accredited in November 2005 and currently manages $>3000$ adults and children. There is a dedicated team with good continuity of nursing, counselling and administration personnel but a high turnover of doctors and allied health workers. Early in the clinic's history it was decided to hold multidisciplinary meetings monthly, in order to understand and deal with difficulties arising from the management of patients on ART. The meetings started in January 2006 and are ongoing.

Patients with perceived problems affecting their optimal management were identified by personnel at the Wellness Clinic during routine consultations, and booked for the bi-weekly multidisciplinary team (MDT) discussion. This team consisted of the physician and family physician involved in the clinic, the unit manager, one nurse, the pharmacist, the social worker and the dietician, one counsellor and a data collector.

\section{THE ROLE OF THE MDT MEETING}

An audit of the minutes of the 2006 MDT meetings was done. All the minutes of the 2006 MDT meetings were examined and patients identified together with the decisions made regarding them. The files of these patients were drawn and the following variables were investigated:

the original and most recent CD4 cell count and viral load (VL)

- reason for being on the MDT's agenda

- if there was an adherence issue, the reason for the poor adherence

- whether support was available or not

- interventions decided upon

the outcomes, where possible, of any interventions.

\section{RESULTS}

According to the minutes, 76 people were discussed. All were adults, 39\% were female, and their mean age was 38 years.

Of the files 13 could not be found for the audit, but reasons for inclusion in the MDT meetings included the following: 6 patients (8\%) had virological failure with no apparent cause, as they had good pill counts at each visit and were physically well. There was documented poor adherence in 5 patients (7\%), reflected in ongoing poor pill counts. Forty-eight patients (63\%) had defaulted treatment for varying lengths of time. In 2 patients (3\%) the reasons for inclusion were not clear from the minutes or the files. Eight (11\%) were included because of alcohol abuse concerns and 7 (9\%) for a variety of other reasons.

Since the group of defaulters was the largest group, it was investigated in more detail. Some of the patients had more than one reason for defaulting, while 13 patients had no real documented reason. Work was cited as being a problem by 7 patients, especially with contract workers being moved to different areas to work. Six patients said that they had had financial problems. However, most of these were already on disability grants. Alcohol played a role in 4 patients and a variety of other reasons were given by the remaining 25 . These included parasuicide, mental retardation, hospital admission, felt sick from pills/not feeling better, incarceration, lost in down-referral process, transfer out, recent birth, painful legs, ashamed to come, domestic upheavals and disputes, traditional medication, amputated leg, staff confidentiality issues, cryptococcal meningitis, and tuberculosis treatment (streptomycin).

In each case, a course of action was discussed and decided upon by the multidisciplinary team.

\section{INTERVENTIONS}

The following were the most common interventions decided upon by the MDT:

- 3 months' adherence counselling and prophylaxis and re-initiate if appropriate

buddy system, e.g. someone to accompany the patient to the clinic visits

social worker intervention

u individual interviews

home visits

- link appropriate patients to Alcoholics Anonymous.

\section{OUTCOMES}

The results of these interventions were then analysed from the available files.

Thirteen files could not be found. Four patients were confirmed as lost to follow-up. Viral loads had decreased in 23 patients after the interventions discussed above, while 17 patients' viral loads had remained in the same range or increased. Viral loads had not been properly done or recorded in 4 patients. Five patients had died, and 10 had other outcomes, e.g. ART stopped.

\section{DISCUSSION}

Following the MDT discussion and intervention, 23 of the available 63 files (36\%) of patients who had been referred to the meeting because of staff and performance concerns indicated that they were doing well at the time of the audit, with virological and clinical stability. This audit revealed that non-adherence or difficulty coping with the ART programme was often caused by 
social and psychological problems. This tends to be a difficult area for health workers to intervene in, and the programmes have to rely on social welfare as well as community-based groups as active partners.

Alcohol appears to have a small but significant influence, as was found in larger studies on adherence. ${ }^{4,6,9}$ More males than females in the MDT group were encountering problems as a result of their alcohol histories, but women were also affected.

Work-related absenteeism often applied to contract workers, especially where artisans were moved for certain periods to other provinces or countries. It remains a crucial part of general and individual counselling that work be taken into consideration and that medication amounts be negotiated, or referral letters written for patients who plan to be away for a period of time.

Deaths are not always reported to the hospital, and a number of the patients recorded as lost to follow-up may in fact have died.

Other ways to minimise loss to follow-up include optimised 'tracking' systems including 'defaulter tracing', down-referrals to satellite clinics closer to home, and involvement of other community-based organisations in tracing patients and doing home visits.

The multidisciplinary team meeting at the Potchefstroom Wellness Clinic did play a role in identifying and solving problems relating to patients on ART. Since the team represents a core of interested people, there is the potential to expand its role to discuss new policies, novel interventions and issues in the clinic and the programme as they arise.

The challenge with providing an optimal service for patients is that each person has their own story and many need individualised attention. Without this understanding, and good relationships between personnel and patients, the battle for optimal care within the ART programmes cannot be won.

\section{REFERENCES}

1. Sherr L. Understanding adherence. J HIV Ther 2000; 5: 30-35.

2. Crespo-Fierro M. Compliance/adherence and care management in HIV disease. J Assoc Nurses AIDS Care 1997; 8: 43-54.

3. Chesney MA, Morin M, Sherr L. Adherence to HIV combination therapy. Soc Sci Med 2000; 50(11): 1599-1605.

4. Mehta S, Moore RD, Graham NMH. Potential factors affecting adherence with HIV therapy. AIDS 1997; 11(14): 1665-1670.

5. Day M. Patient adherence to HAART regimens: Challenges for physician assistants and health care providers. The Internet Journal of Academic Physician Assistants 2003; 3(1). http://www.ispub.com/journal/the_internet_journal_ of_academic_physician_assistants/volume_3_number_1_7/article/patient_ adherence_to_haart_regimens_challenges_for_physician_assistants_and_ health_care_providers.html (accessed 18 June 2009).

6. Fogarty L, Roter D, Larson S, Burke J, Gillespie J, Levy R. Patient adherence to HIV medication regimens: a review of published and abstract reports. Patient Educ Couns 2002; 46(2): 91-92

7. Nischal KC, Khopkar U, Saple DG. Improving adherence to antiretroviral therapy. Indian J Dermatol Venereol Leprol 2005; 71: 316-320.

8. Fedder DO. Drug use in the elderly: issues of noncompliance. Drug Intell Clin Pharmacol 1984, 18: 158-162.

9. Kissinger P, Cohen D, Brandon W, Rice J, Morse A, Clark R. Compliance with public sector HIV medical care. J Natl Med Assoc 1995; 87: 19-24.

\section{A few patient stories}

A young woman who had started ART had had a boyfriend for 10 years. He suddenly left her for another woman. She had repeated counselling but became profoundly depressed, which influenced her adherence.

An older married couple were both patients at the Wellness Clinic and on ART, but the husband was apparently being abused by his wife and eventually died in hospital from an HIV-related infection. The wife never came back in spite of intensive counselling and support from the clinic personnel.

Two mothers insisted on their daughters taking traditional medicines and stopping HAART. Both young women eventually returned to the clinic in spite of this pressure.

$A$ very problematic patient, who is still receiving HAART, returns to the clinic with repeated STIs. She has been caught lying about her pills and pill counts, comes and goes as she wishes, and is constantly abusive towards clinic staff.

10. Young J, Howard Z, Shepler L. Medication noncompliance in schizophrenia: codification and update. Bull Am Acad Psychiatry Law 1986; 14: 105-122.

11. Pugh R. An association between hostility and poor adherence to treatment in patients suffering from depression. BrJ Med Psychol 1983; 56: 205-208.

12. Singh N, Squier C, Hayes P. Determinants of compliance in patients with HIV: prospective assessment with implications for enhancing compliance. Paper presented at the 34th Interscience Conference on Antimicrobial Agents and Chemotherapy, Orlando, Fla, 4 - 7 October 1994.

13. Youssef F. Adherence to therapy in psychiatric patients: an empirical investigation. Int J Nurs Stud 1984; 21: 51-57.

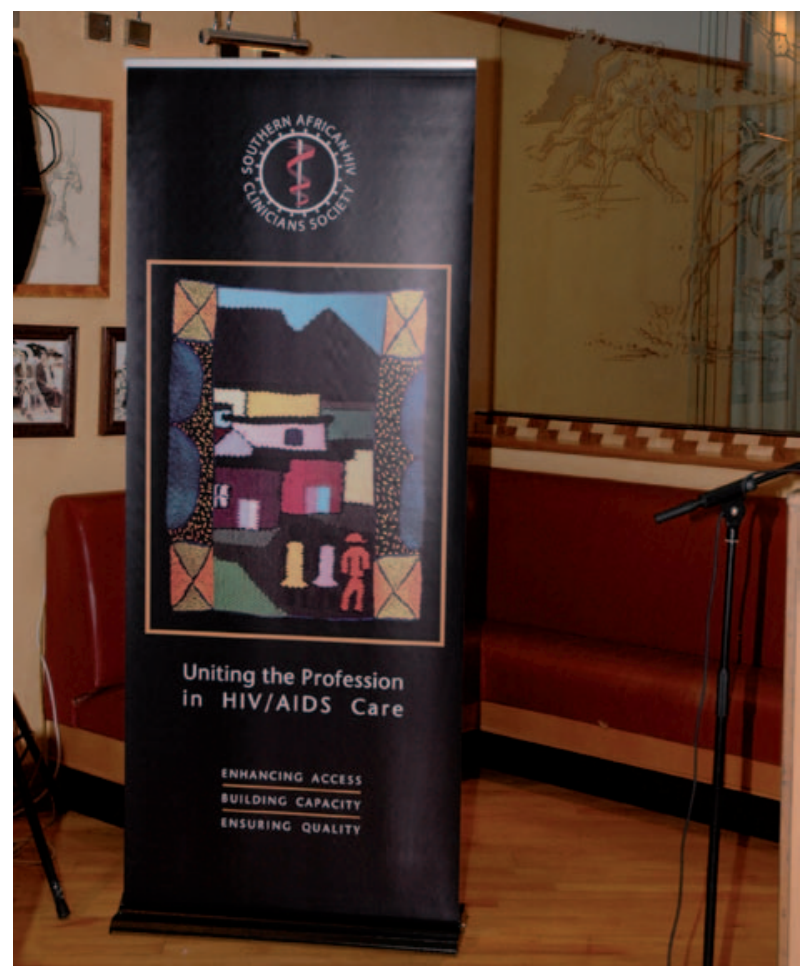

